\title{
Chlorpropamide and fibrinolytic activity in maturity onset diabetes mellitus
}

\author{
William D. AleXander \\ M.B., M.R.C.P.
}

Geraldine Price

\author{
R. T. WENSLEY \\ M.R.C.Path., M.R.C.P. \\ M. HARTOG \\ M.D., F.R.C.P.
}

\section{University Department of Medicine, Bristol Royal Infirmary, Bristol}

\section{Summary}

This study was performed to assess the effect of chlorpropamide therapy on the fibrinolytic activity of blood of maturity onset diabetics. Normal controls were also studied and the results compared with diabetics. Diabetics were found to have deficient fibrinolytic activity compared with non-diabetics but chlorpropamide did not appear significantly to affect this deficiency either in males or females when given therapeutically over a 6-month period.

\section{Introduction}

Diabetics are more prone to cardiovascular morbidity than non-diabetics. Reduced fibrinolysis has been considered as a possibly relevant factor but investigations have produced conflicting results (Farid et al., 1974; Fearnley, Vincent and Chakrabarti, 1959; Denborough and Paterson, 1962; Hathorn, Gillman and Campbell, 1961; Fearnley, Chakrabarti and Avis, 1963; MacKay and Hume, 1964). In 1970, the University Group Diabetes Program in the United States published data suggesting that sulphonylurea therapy might increase the tendency to cardiovascular death in diabetics (University Group Diabetes Program, 1970). Studies relating changes in fibrinolysis and chlorpropamide therapy have also shown conflicting results (Farid et al., 1974; MacKay and Hume, 1964; Tsapogas, Cotton and Flute, 1962; Fearnley, Chakrabarti and Vincent, 1960; Fearnley and Chakrabarti, 1964). Many factors are known to affect fibrinolytic activity (Fearnley, 1969) and the authors felt that the inconsistencies of results of previous studies on diabetics might have been due to failure to take these into account. They have attempted to overcome this problem by studying the same diabetics before and after chlorpropamide therapy, all blood samples being taken under similar conditions. The fibrinolytic activity was measured by dilute blood clot lysis time (see below) which shows very little day-to-day variation in any individual when measured at the

Correspondence: Dr William D. Alexander, University Hospital of Wales, Heath Park, Cardiff. same time of day and under similar conditions (Fearnley, 1969). Results in diabetics were compared with those in normal non-diabetic controls.

\section{Materials and methods}

\section{(a) Subjects studied}

(1) Diabetics. Diabetics were selected from the diabetic clinic as being in need of sulphonylurea therapy, i.e. maturity onset diabetes uncontrolled (fasting blood glucose $>140 \mathrm{mg} / 100 \mathrm{ml}$ ) by diet alone in non-obese subjects. Nine male (mean age 58 years, range 50-70) and nine female subjects (mean age 63 years, range 54-70) were studied. No patient had overt cardiovascular disease. Blood glucose, total cholesterol and triglycerides, plasma fibrinogen, activated partial thromboplastin time (APPT) and dilute blood clot lysis time (DCL) were estimated before and after 6 months' continuous therapy with chlorpropamide in a dose of $250 \mathrm{mg}$ daily.

(2) Controls. Asymptomatic volunteers matched for age with the diabetic subjects were used as controls. There were sixteen female (mean age 59 years, range 50-70) and eighteen male subjects (mean age 60 years, range 50-70) in this group.

\section{(b) Conditions of blood sampling}

All samples were taken between 9 and 9.30 a.m. after a 15-min rest. All subjects had fasted overnight.

\section{(c) Methods of analysis}

(1) Blood glucose on a Technicon SMR-12 autoanalyser by the rapid automated method of Moore, Barnes and Pennock (1972).

(2) Cholesterol and triglycerides on a Technicon autoanalyser-cholesterol by a modification of the Lieberman-Burchard method and triglycerides by a standard semi-automated Technicon method (Kessler and Lederer, 1965).

(3) DCL as described by Fearnley and Tweed (1953).

(4) Plasma fibrinogen using the clot weight method (Fearnley and Chakrabarti, 1966).

(5) APPT by the method of Eastham (1962). 


\section{Results}

(a) Blood glucose in the diabetics (Table 1)

The blood glucose fell significantly $(P<0.0025)$ after chlorpropamide treatment. Males and females responded equally. There was no significant difference between the initial and final blood glucose levels between male and female patients.

(b) Serum cholesterol, triglycerides, plasma fibrinogen and APPT (Table 2)

No significant change was observed in any of these parameters after treatment. There was no significant difference in the initial or final levels between male and female patients.

(c) Fibrinolysis (Table 3)

Before chlorpropamide, males had lower DCL times than did females; after chlorpropamide, males had higher DCL times than did females. DCL time showed an increase in males and a decrease in females after chlorpropamide treatment. However, none of these effects was significant and the changes in males and females were not significantly different from each other.

(d) Fibrinolvsis in normal as compared with diabetic subjects before and after chlorpropamide (Table 4)

DCL time did not differ between normal males and females. The values in the diabetics were higher than in normals-significantly so in males after $(\boldsymbol{P}<$ $0.005)$ and in females before chlorpropamide treatment $(P<0.025)$.

Since there is no clear difference in fibrinolysis between male and female diabetics and no definite effect of chlorpropamide in either the male or female subjects (see (c) above) the results in the normal

TABLE 1. Blood glucose level before and after chlorpropamide treatment (nine males, nine females)

\begin{tabular}{lcc}
\hline & \multicolumn{2}{c}{$\begin{array}{c}\text { Mean fasting blood glucose } \\
(\mathrm{mg} / 100 \mathrm{ml})(\mathrm{mean} \pm 1 \text { s.d. })\end{array}$} \\
\cline { 2 - 3 } \multicolumn{1}{c}{ Treatment } & Male & Female \\
\hline Before chlorpropamide & $190( \pm 25 \cdot 1)$ & $229( \pm 70 \cdot 2)$ \\
After chlorpropamide & $127( \pm 22 \cdot 7)$ & $124( \pm 30 \cdot 2)$ \\
\hline
\end{tabular}

subjects have also been compared with all those from the diabetics, i.e. the mean of the DCL time before and after treatment in each patient (Table 5). It can be seen that DCL times were significantly prolonged in diabetics compared with the normals $(P=<0.01$ for the males and $P=<0.005$ for the females). This difference could not be accounted for by changes in plasma fibrinogen or APPT (Table 6), which showed no significant difference between the groups.

\section{(e) Clinical aspects}

During the treatment period no cardiovascular के complications occurred in any subject. There was no $\overrightarrow{0}$ significant weight change in any subject over the period of the study.

\section{Discussion}

Previous studies aimed at investigating the effect of chlorpropamide therapy on fibrinolytic activity in $\mathrm{N}$ diabetes have shown inconsistent results such as of enhancement of fibrinolysis (Tsapogas et al., 1962; Fearnley et al., 1960); early enhancement with late o resistance (Fearnley and Chakrabarty, 1964); en- $\vec{\circ}$ hancement in males and no change in females $\frac{}{J}$ (MacKay and Hume, 1964); and enhancement in $\overrightarrow{\vec{z}}$ males and inhibition in females (Farid et al., 1974). The authors consider that these inconsistencies were partly due to inadequately standardized condition of blood sampling. Previous studies have also tende to compare groups of diabetics on different treatmen regimes. Such groups are heterogeneous since the initial choice of treatment, be it with diet, insulin, sulphonylureas, biguanides or combinations of these, will depend upon many factors such as age, $\Phi$ weight, severity of disease, presence of complications $\overrightarrow{\vec{F}}$ and others which may themselves affect fibrinolysis. This problem was overcome by comparing the same diabetics before and after chlorpropamide therapy and to the authors' knowledge this has not previously been done. Blood glucose was the only parameter to 3 change significantly after 6 months' chlorpropamide. This is important as it shows that the subjects were 3 taking the drug and that the desired effect upon the 8 diabetes had been produced. This fall in blood glucose is unlikely to have affected fibrinolytic activity

TABLE 2. Serum triglycerides, cholesterol, plasma fibrinogen and APPT before and after chlorpropamide treatment (nine males, nine females)

\begin{tabular}{|c|c|c|c|c|c|c|c|c|}
\hline \multirow[b]{2}{*}{ Treatment } & \multicolumn{2}{|c|}{$\begin{array}{c}\text { Cholesterol } \\
(\mathrm{mg} / 100 \mathrm{ml}) \\
\text { (mean } \pm 1 \text { s.d.) }\end{array}$} & \multicolumn{2}{|c|}{$\begin{array}{l}\text { Triglycerides } \\
(\mathrm{mg} / 100 \mathrm{ml}) \\
\text { (mean } \pm 1 \text { s.d. }\end{array}$} & \multicolumn{2}{|c|}{$\begin{array}{c}\text { Fibrinogen } \\
(\mathrm{mg} / 100 \mathrm{ml}) \\
\text { (mean } \pm 1 \text { s.d.) }\end{array}$} & \multicolumn{2}{|c|}{$\begin{array}{c}\text { APPT } \\
(\mathrm{sec}) \\
\text { (mean } \pm 1 \text { s.d.) }\end{array}$} \\
\hline & Male & Female & Male & Female & Male & Female & Male & Female \\
\hline Before chlorpropamide & $\begin{array}{c}236 \\
( \pm 63)\end{array}$ & $\begin{array}{c}226 \\
( \pm 65)\end{array}$ & $\begin{array}{c}109 \\
( \pm 41 \cdot 4)\end{array}$ & $\begin{array}{c}123 \\
( \pm 41 \cdot 5)\end{array}$ & $\begin{array}{c}346 \\
( \pm 36)\end{array}$ & $\begin{array}{c}371 \\
( \pm 56)\end{array}$ & $\begin{array}{c}35 \cdot 8 \\
( \pm 3 \cdot 9)\end{array}$ & $\begin{array}{c}36 \cdot 2 \\
( \pm 5 \cdot 1)\end{array}$ \\
\hline After chlorpropamide & $\begin{array}{c}227 \\
( \pm 35 \cdot 5)\end{array}$ & $\begin{array}{c}241 \\
( \pm 63 \cdot 5)\end{array}$ & $\begin{array}{c}118 \\
( \pm 40)\end{array}$ & $\begin{array}{c}100 \\
( \pm 37)\end{array}$ & $\begin{array}{c}319 \\
( \pm 54 \cdot 2)\end{array}$ & $\begin{array}{c}355 \\
( \pm 39 \cdot 3)\end{array}$ & $\begin{array}{l}35 \cdot 5 \\
( \pm 2)\end{array}$ & $\begin{array}{c}35 \cdot 7 \\
( \pm 2 \cdot 6)\end{array}$ \\
\hline
\end{tabular}


TABLE 6. APPT and plasma fibrinogen in normal controls and diabetics treated with diet and/or diet + chlorpropamide (nine male and nine female diabetics, eighteen male and sixteen female controls)

\begin{tabular}{lccccc}
\hline & \multicolumn{2}{c}{ APPT $(\mathrm{sec})($ mean \pm 1 s.d.) } & & \multicolumn{2}{c}{$\begin{array}{c}\text { Fibrinogen }(\mathrm{mg} / 100 \mathrm{ml}) \\
(\text { mean } \pm 1 \text { s.d.) }\end{array}$} \\
\cline { 2 - 3 } \cline { 5 - 6 } & Male & Female & & Male & Female \\
\hline Normals & $36.4( \pm 3 \cdot 3)$ & $35 \cdot 2( \pm 3 \cdot 2)$ & & $337( \pm 65 \cdot 5)$ & $333( \pm 68)$ \\
Diabetics & $35 \cdot 7( \pm 3 \cdot 0)$ & $35.9( \pm 3 \cdot 9)$ & & $333( \pm 47)$ & $363( \pm 47)$ \\
\hline
\end{tabular}

itself as previous studies have shown that alterations in blood glucose do not affect fibrinolysis in the long term (Denborough and Paterson, 1962; Fearnley et al., 1963; Fearnley et al., 1960).

The results show that chlorpropamide has no significant effect on fibrinolytic activity when given therapeutically to diabetics, be they male or female. Diabetics do, however, appear to have reduced blood fibrinolytic activity when compared with normal age-matched controls. This series is small and perhaps larger numbers should be studied to settle finally this potentially important subject, but it is concluded that although diabetics have a deficient fibrinolytic system this deficiency is not adversely affected by treatment with chlorpropamide. If sulphonylureas produce an increase in cardiovascular

TABle 3. Dilute clot lysis time (DCL) before and after chlorpropamide treatment (nine males, nine females)

\begin{tabular}{lcc}
\hline \multirow{2}{*}{\multicolumn{1}{c}{ Treatment }} & \multicolumn{2}{c}{ DCL (hr) (mean \pm 1 s.d.) } \\
\cline { 2 - 3 } & Male & Female \\
\hline Before chlorpropamide & $10 \cdot 02( \pm 6 \cdot 0)$ & $11 \cdot 25( \pm 4 \cdot 8)$ \\
After chlorpropamide & $12 \cdot 83( \pm 4 \cdot 3)$ & $9 \cdot 1( \pm 5 \cdot 7)$ \\
\hline
\end{tabular}

TABLE 4. Dilute clot lysis time (DCL) in normal controls and diabetics before and after chlorpropamide treatment (nine male and nine female diabetics, eighteen male and sixteen female controls)

\begin{tabular}{lccc}
\hline & \multicolumn{3}{c}{ DCL (hr) (mean \pm 1 s.d.) } \\
\cline { 2 - 4 } Sex & $\begin{array}{c}\text { Control } \\
\text { subjects }\end{array}$ & $\begin{array}{c}\text { Diabetics } \\
\text { before } \\
\text { chlorpropamide }\end{array}$ & $\begin{array}{c}\text { Diabetics } \\
\text { after } \\
\text { chlorpropamide }\end{array}$ \\
\hline Male & $7 \cdot 36( \pm 3 \cdot 9)$ & $10.02( \pm 6 \cdot 0)$ & $12 \cdot 83( \pm 419)$ \\
Female & $6.93( \pm 4 \cdot 4)$ & $11 \cdot 25( \pm 4 \cdot 8)$ & $9 \cdot 1 \quad( \pm 5 \cdot 7)$ \\
\hline
\end{tabular}

TABLE 5. Dilute clot lysis time (DCL) in normal controls and diabetics treated with diet and/or diet + chlorpropamide

\begin{tabular}{|c|c|c|c|}
\hline \multicolumn{2}{|c|}{$\begin{array}{l}\text { DCL (hr)-Controls } \\
\text { (mean } \pm 1 \text { s.d.) }\end{array}$} & \multicolumn{2}{|c|}{$\begin{array}{l}\text { DCL }(\mathrm{hr}) \text {-Diabetics } \\
(\text { mean } \pm 1 \text { s.d. })\end{array}$} \\
\hline $\begin{array}{c}\text { Male } \\
7 \cdot 36( \pm 3 \cdot 9)\end{array}$ & $\begin{array}{c}\text { Female } \\
6.93( \pm 4.4)\end{array}$ & $\begin{array}{c}\text { Male } \\
11 \cdot 43( \pm 5 \cdot 5)\end{array}$ & $\begin{array}{c}\text { Female } \\
10 \cdot 19( \pm 5 \cdot 2)\end{array}$ \\
\hline
\end{tabular}

morbidity it is not mediated through their effect on the fibrinolytic system.

\section{Acknowledgments}

We would like to thank the United Bristol Hospitals for financial assistance, and C. A. Hold and D. S. Cadogan for secretarial expertise.

\section{References}

Denborough, M.A. \& Paterson, B. (1962) Clearing factor, fibrinolysis and blood lipids in diabetes mellitus. Clinical Science, 23, 485.

EASTHAM, R.D. (1962) An improved plasma recalcified clotting test and its modification as a simple rapid heparin retarded clotting test. Journal of Clinical Pathology, 15, 86.

Farid, N.R., Anderson, J., Martin, A. \& Weightman, D. (1974) Fibrinolytic activity and treatment of diabetes. Lancet, i, 631.

FeARNLey, G.R. (1969) Recent Advances in Blood Coagulation (1st Edn), pp. 239-241. Churchill, London.

Fearnley, G.R. \& Chakrabarti, R. (1964) Pharmacological enhancement of fibrinolytic activity in blood. Journal of Clinical Pathology, 17, 328.

Fearnley, G.R. \& Chakrabarti, R. (1966) Fibrinolytic treatment of rheumatoid arthritis with phenformin plus ethyloestrenol. Lancet, ii, 757.

Fearnley, G.R., Chakrabarti, R. \& Avis, P.R.D. (1963) Blood fibrinolytic activity in diabetes and its bearing on ischaemic heart disease and obesity. British Medical Journal, 1, 921.

Fearnley, G.R., Chakrabarti, R. \& Vincent, C.T. (1960) Effects of sulphonylureas on fibrinolysis. Lancet, ii, 622.

FEARNLEY, G.R. \& TWEED, J.M. (1953) Evidence of an active fibrinolytic enzyme in the plasma of normal people, with observations on inhibition, associated with the presence of calcium. Clinical Science, 12, 81 .

Fearnley, G.R., Vincent, C.T. \& Chakrabarti, R. (1959) Reduction of blood fibrinolytic activity in diabetes by insulin. Lancet, ii, 1067.

HathoRn, M., Gillman, T. \& Campbell, G.D. (1961) Blood lipids, mucoproteins and fibrinolytic activity in diabetic Indians and Africans in Natal. Lancet, i, 1314.

KessLeR, G. \& LEDERER, J. (1965) Automation in Analytical Chemistry, p. 341. Ed. Sheggs, New York.

MaCKAY, N. \& Hume, R. (1964) Fibrinolytic activity in diabetes. Scottish Medical Journal, 9, 359.

Moore, G.R., Barnes, I.C. \& Pennock, C.A. (1972) An improved rapid automated method for the estimation of blood glucose. Clinica chimica acta, 41, 439.

Tsapogas, M.J., Cotton, L.T. \& Flute, P.T. (1962) Effects of chlorpropamide on intermittent claudication and fibrinolysis. Lancet, i, 1213.

University Group Diabetes Program (1970) A study of the effects of hypoglycemic agents on vascular complications in patients with adult onset diabetes. Diabetes, 19 (Suppl. 2), 789. 